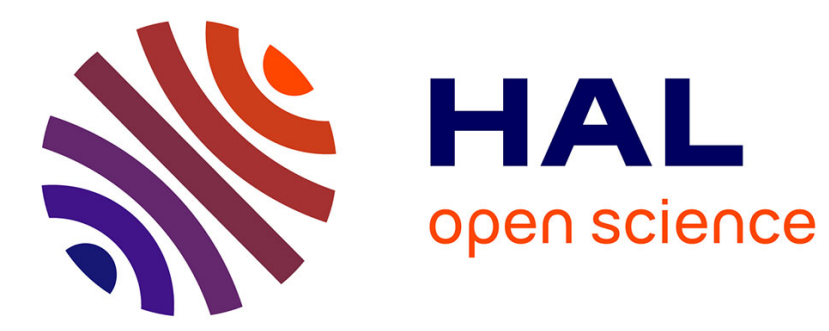

\title{
Detection and Pharmacological Modulation of Nicotinamide Mononucleotide (NMN) and
}

\author{
Laura Formentini, Flavio Moroni, Alberto Chiarugi
}

\section{To cite this version:}

Laura Formentini, Flavio Moroni, Alberto Chiarugi. Detection and Pharmacological Modulation of Nicotinamide Mononucleotide (NMN) and. Biochemical Pharmacology, 2009, 77 (10), pp.1612. 10.1016/j.bcp.2009.02.017 . hal-00493496

\section{HAL Id: hal-00493496 \\ https://hal.science/hal-00493496}

Submitted on 19 Jun 2010

HAL is a multi-disciplinary open access archive for the deposit and dissemination of scientific research documents, whether they are published or not. The documents may come from teaching and research institutions in France or abroad, or from public or private research centers.
L'archive ouverte pluridisciplinaire HAL, est destinée au dépôt et à la diffusion de documents scientifiques de niveau recherche, publiés ou non, émanant des établissements d'enseignement et de recherche français ou étrangers, des laboratoires publics ou privés. 


\section{Accepted Manuscript}

Title: Detection and Pharmacological Modulation of

Nicotinamide Mononucleotide (NMN) in vitro and in vivo

Authors: Laura Formentini, Flavio Moroni, Alberto Chiarugi

PII: $\quad$ S0006-2952(09)00118-X

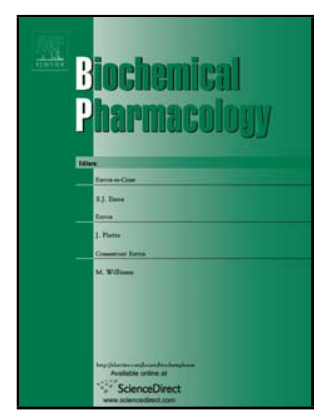

DOI: doi:10.1016/j.bcp.2009.02.017

Reference:

BCP 10097

To appear in: $\quad B C P$

Received date: $\quad 24-12-2008$

Revised date: $\quad$ 18-2-2009

Accepted date: $\quad$ 19-2-2009

Please cite this article as: Formentini L, Moroni F, Chiarugi A, Detection and Pharmacological Modulation of Nicotinamide Mononucleotide (NMN) in vitro and in vivo, Biochemical Pharmacology (2008), doi:10.1016/j.bcp.2009.02.017

This is a PDF file of an unedited manuscript that has been accepted for publication. As a service to our customers we are providing this early version of the manuscript. The manuscript will undergo copyediting, typesetting, and review of the resulting proof before it is published in its final form. Please note that during the production process errors may be discovered which could affect the content, and all legal disclaimers that apply to the journal pertain. 


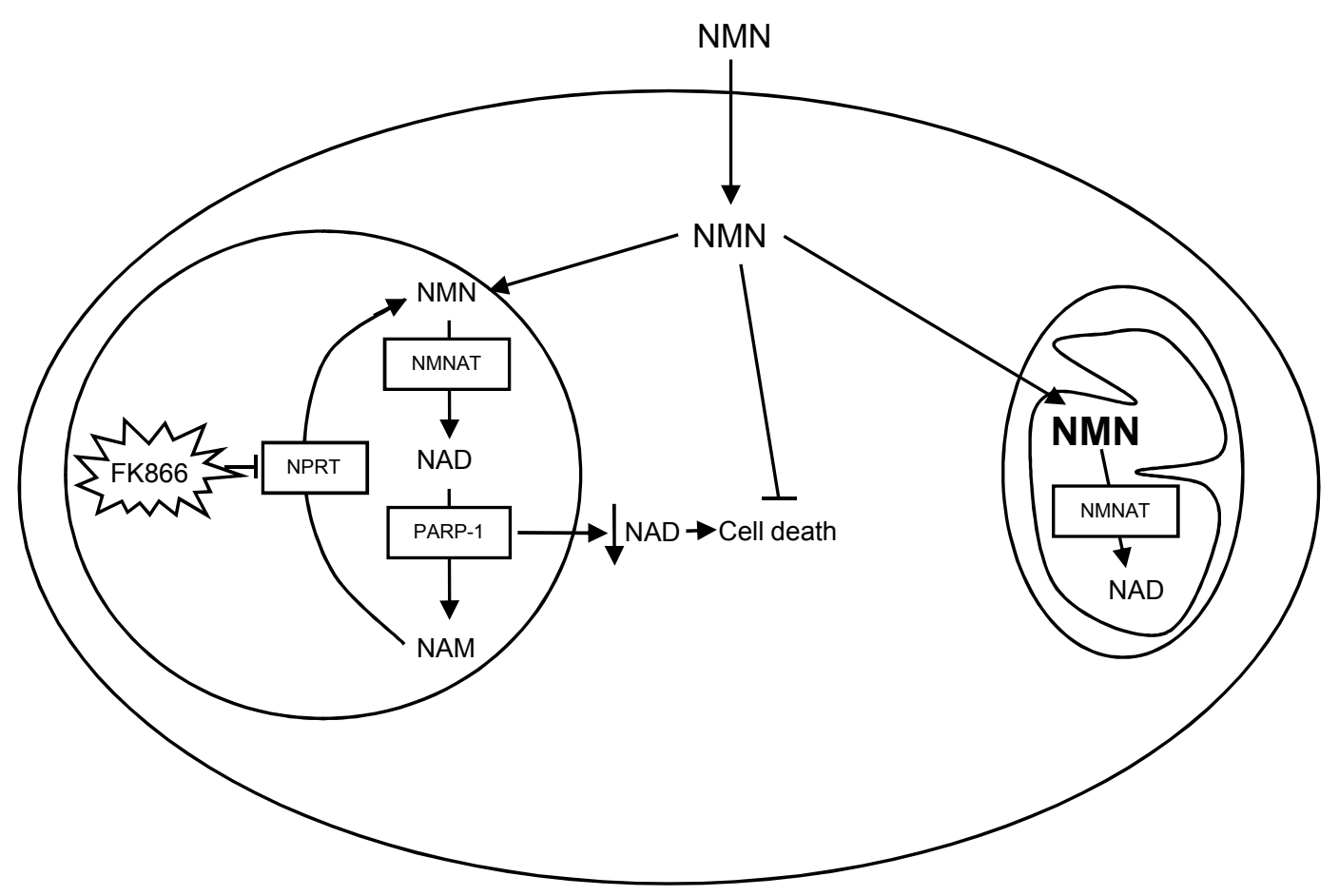

Page 1 of 26 


\section{Detection and Pharmacological Modulation of Nicotinamide Mononucleotide (NMN) in vitro and in vivo}

1

2

3

4

5

6

7

8

9

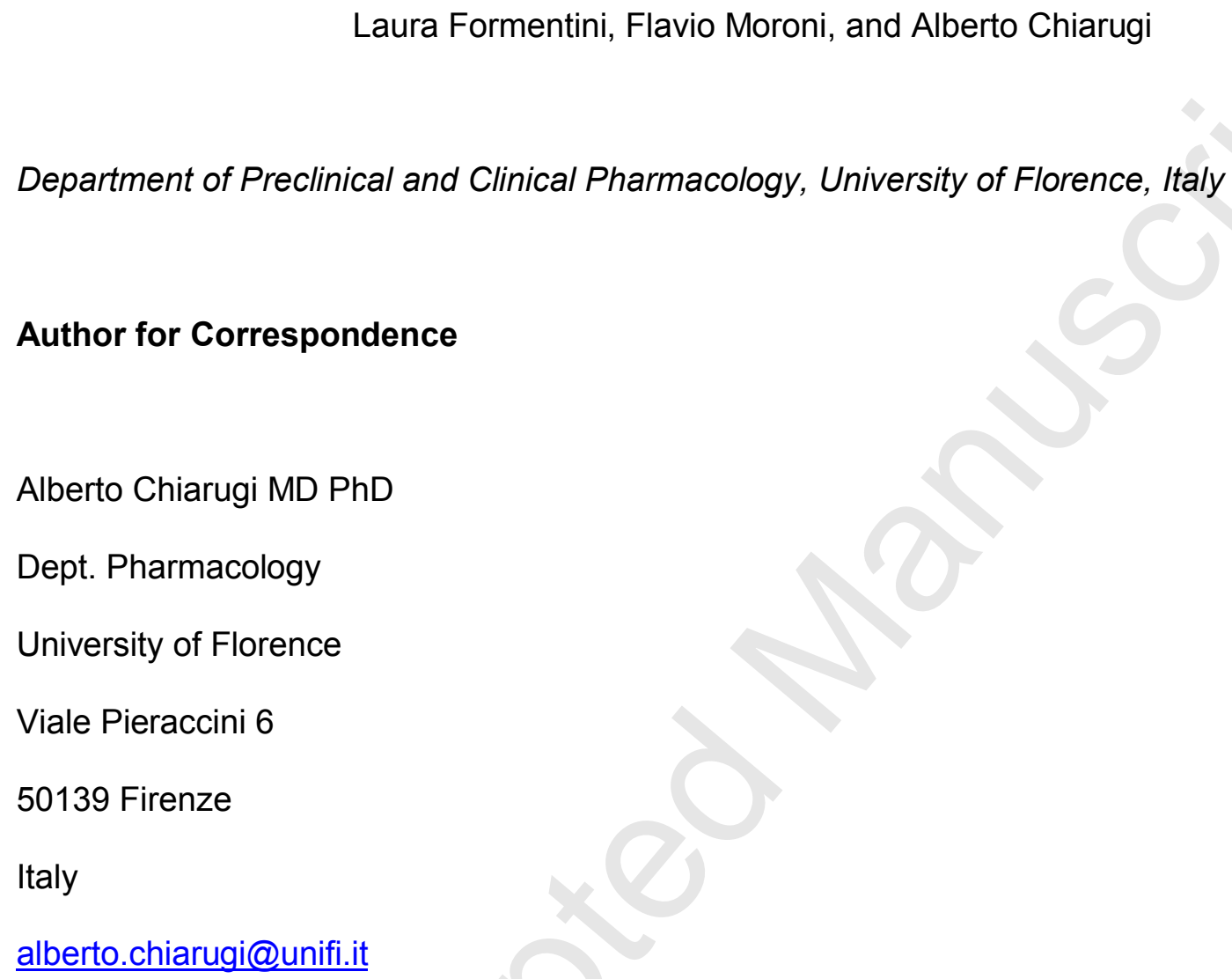




\begin{abstract}
The emerging key role of NAD consuming enzymes in cell biology has renewed the interest in NAD resynthesis through the rescue pathways. The first step of the nicotinamide-dependent NAD rescue pathway is operated by nicotinamide phosphoribosyl transferase (NaPRT) forming nicotinamide mononucleotide (NMN). Because of the difficulties in measuring NMN, numerous open questions exist about the pathophysiological relevance of NaPRT and NMN itself. Here, we describe a new method of fluorimetric NMN detection upon derivatization of its alkylpyridinium group with acetophenone. By adopting this method, we analyzed the kinetics of nicotinamidedependent NAD recycling in HeLa and U937 cells. Measurement of NMN contents in subcellular fractions revealed that the nucleotide is highly enriched in mitochondria, suggesting intramitochondrial NAD synthesis. NMN increases in cells undergoing hyperactivation of the NADconsuming enzyme poly(ADP-ribose) polymerase (PARP)-1, or exposed to gallotannin, a putative inhibitor of NMN-adenylyl transferases. Evidence that the inhibitor of NAD resynthesis FK866 selectively inhibits NaPRT having no effect on NMNAT activity is also provided. Importantly, NMN reduces NAD and ATP depletion in cells undergoing PARP-1 hyperactivation, significantly delaying cell death. Finally, we show that a single injection of FK866 in the mouse induces long-lasting (up to $16 \mathrm{~h}$ ) but mild $(20 \%)$ reduction of NMN contents in different organs, suggesting slow rate of basal NAD consumption in vivo. Data provide new information on the biochemistry and pharmacology of NAD biosynthesis, allowing a better understanding of pyridine nucleotide metabolism.
\end{abstract}

Key Words: NAD, PARP, mitochondria, FK866, NMNAT, NaPRT 


\section{Introduction}

Pyridine nucleotides have long been considered hydride ion carriers exclusively involved in oxidoreduction reactions. However, the recent identification of different enzyme families having nicotinamide adenine dinucleotide (NAD) as substrate has significantly renewed the interest in the biochemistry and pharmacology of pyridine nucleotides [1-3]. In particular, being these enzyme families responsible for the irreversible transformation of NAD into different products, attention has been focused on the mechanisms of NAD resynthesis into eukaryotic cells. Classically, two metabolic pathways regulate the formation of NAD in mammalian cells; i.e. the de novo (also called the "kynurenine") pathway, leading to NAD from tryptophan, and the rescue pathway using the nicotinamide moiety produced as a by-product by the NAD-consuming enzymes. The PreissHandler route also contributes to pyridine nucleotide formation, transforming nicotinic acid absorbed from the gut into NAD $[1 ; 4 ; 5]$. Notably, a recently identified metabolic route leading to NAD formation from nicotinamide riboside also exists [6;7]. Conversely, vertebrates are unable to convert nicotinamide into nicotinic acid [5].

A central metabolite in NAD resynthesis is nicotinamide mononucleotide (NMN, Fig. 1). It is produced by nicotinamide phosphoribosyl transferase (NaPRT) and by nicotinamide riboside kinase (NRK). NMN is then converted into NAD by three isoforms of NMN-adenilyl transferase (NMNAT). Recently, NaPRT received much attention by the scientific community because of its pleiotypic functions. Specifically, besides being an intracellular enzyme involved in NAD resynthesis, the protein has been also identified as a released factor behaving as an adipokine and as an inflammatory cytokine [8]. Adipokines are fat tissue-derived hormones with central roles in metabolism and disease pathogenesis. A protein with the same amino acid structure of NaPRT has been identified as a $52 \mathrm{kDa}$ release product of visceral fat and therefore called visfatin [9;10]. Controversies exist as for the endocrine properties of visfatin/NaPRT. Although originally identified as an insulin receptor-interacting protein able to improve glucose-stimulated insulin secretion, the protein is now thought to be devoid of insulin receptor-interacting properties but still able to regulate glucose homeostasis by promoting pancreatic islet insulin secretion. Of note, these properties are entirely dependent on NMN production by secreted visfatin/NaPRT [11]. The 
secreted protein can also behave as a cytokine called Pre-B cell colony-enhancing factor (PBEF). NaPRT/visfatin/PBEF is released by various immune cells, promotes TNF $\alpha$, IL1 $\beta$ and IL-6 production, and is increased in the sera of patients affected by sepsis, acute lung injury, myocardial infarction, rheumatoid arthritis and inflammatory bowel disease. The protein is also able to inhibit neutrophil apoptosis, thereby promoting the immune response [12]. Whether NMN production contributes to the immunoregulatory functions of NaPRT/visfatin/PBEF is still unknown but a specific receptor has not been identified. Also, the permeability of NMN through the plasma membrane is not clear and, again, a possible $\mathrm{NMN}$-interacting receptor waits to be identified. Given the potential relevance of NaPRT/visfatin/PBEF to pathophysiology, several ELISA kit able to detect the protein have been recently made commercially available. Yet, these kits have different sensitivities and are heterogeneous in nature. These inconsistencies are probably responsible for the apparent contrasting properties of secreted NaPRT/visfatin/PBEF present in the literature. Also, since the functional properties of NaPRT/visfatin/PBEF may in part depend on its enzymatic activity [11;13], evaluation of intra- as well as extracellular NMN production can certainly help understanding the pathophysiological role of the protein. Unfortunately, analytical determination of NMN is difficult because of its physicochemical features. Indeed, very few studies have measured NaPRT activity and/or NMN concentrations in biological fluids or tissue extracts using radioactive or complex HPLC/MS techniques [11;13;14]. In the present study we provide new information on NMN metabolism and pharmacological modulation by using an original method of NMN measurement as well as the newly identified inhibitor of NaPRT (E)-N-[4-(1-benzoylpiperidin4-yl) butyl]-3-(pyridin-3-yl) acrilamide (FK866) [15;16].

\section{Materials and methods}

\subsection{Cell culture and treatment}

Unless otherwise stated, all chemicals and cell culture products were from Sigma (Milan, Italy). HeLa or U937 cells were cultured in Dulbecco's modified Eagle's medium (DMEM) supplemented with $2 \mathrm{mM}$ glutamine, $10 \%$ fetal bovine serum and antibiotics. Cultures were brought to $50-70 \%$ confluence and exposed to N-methyl-N'-nitro-N-nitrosoguanidine (MNNG, $100 \mu \mathrm{M})$, nicotinamide 


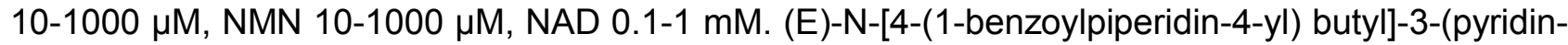
3-yl) acrilamide (FK866, 1-100 $\mu \mathrm{M}$ ) was obtained from $\mathrm{NIH}$, Bethesda, USA. Cell viability was evaluated by measuring lactate dehydrogenase $(\mathrm{LDH})$ release in the incubating media or reduction of methylthiazolyl tetrazolium (MTT) and described [17]. An inverted Nikon TE-2000U microscope equipped with a CDD camera was used for cell visualization.

\subsection{Cell fractionation}

As previously described [17], cells were disrupted using a glass/glass homogenizer in $500 \mu$ of buffer A (Tris $\mathrm{HCl} 50 \mathrm{mM}$, pH 7.4, mannitol $225 \mathrm{mM}$, saccarose $75 \mathrm{mM}, 1 \mathrm{mM}$ PMSF, $10 \mu \mathrm{l}$ of protease inhibitor cocktail), and centrifuged at $600 \mathrm{~g}$ to obtain the nuclear pellet. Supernatants were centrifuged at $12000 \mathrm{~g}$ to obtain the mitochondrial pellet and the cytosolic fraction. Cell fractions were then processed for NMN determination as described above.

\subsection{NMN, NAD and ATP measurement}

Ultra pure NMN standards (Sigma, Milan, Italy) were dissolved in water and solutions analyzed by HPLC with UV or fluorimetric detection. For UV detection, cells grown in a 48 well plate were scraped with $100 \mu \mathrm{l}$ of $\mathrm{HCl} 0.6$. The cell extract was centrifuged at $14.000 \mathrm{~g} / 5 \mathrm{~min}$ and $25 \mu \mathrm{L}$ of the supernatant injected in an HPLC system consisting in a mobile phase of $0.1 \mathrm{M}$ buffer phosphate $\mathrm{pH}$ 6.5, $1 \%$ acetonitrile, $10 \mathrm{mM}$ tetra butyl-ammonium bromide (TBAB), a Supelco $25 \mathrm{~cm}$ column $(5 \mu \mathrm{m})$ and an UV detector (Perkin Elmer) set at $260 \mathrm{~nm}$. For fluorimetric detection, we modified a method previously described [18]. Briefly, cells grown in a 48 well plate were lysed with $100 \mu l$ of $\mathrm{HClO}_{4} 1 \mathrm{~N}$, whereas mouse organs were sonicated in $\mathrm{HCLO}_{4} 1 \mathrm{~N}(1: 4 \mathrm{w} / \mathrm{v})$. Then, $100 \mu \mathrm{l}$ of the extract were neutralized with $\mathrm{KOH} 1 \mathrm{~N}$ and, after $5 \mathrm{~min}$, additional $100 \mu \mathrm{l}$ of $0.1 \mathrm{M}$ bicine $\mathrm{pH} 7.4$ were added. The cell extract was centrifuged at $14.000 \mathrm{~g} / 5 \mathrm{~min}$ and $10 \mu \mathrm{L}$ of the supernatant were mixed with $100 \mu \mathrm{l}$ of $\mathrm{KOH} 1 \mathrm{~N}$ and $50 \mu \mathrm{l}$ of acetophenone. The solution was incubated for $15 \mathrm{~min}$ at $4^{\circ} \mathrm{C}$, then $100 \mu \mathrm{l}$ formic acid were added and the solution incubated $5 \mathrm{~min}$ at $100{ }^{\circ} \mathrm{C}$. By means of this derivatization procedure, NMN is converted into a highly fluorescent compound as shown in Fig. 1. Excitation and emission spectra of the fluorescent compound were determined by means of 
a spectro fluorophotometer RF5000 (Shimadzu, Milan, Italy). Samples were injected into the HPLC system consisting in a mobile phase of $0.1 \mathrm{M}$ buffer phosphate $\mathrm{pH} 6.5,10 \%$ acetonitrile, a Supelco $25 \mathrm{~cm}$ column $(5 \mu \mathrm{m})$ and a fluorimetric detector (Perkin Elmer) with excitation and emission wavelength of 332 and $454 \mathrm{~nm}$, respectively.

NAD contents were quantified by means of an enzymatic cycling procedure as described [19]. ATP was measured by the ATPlight kit (Perkin Elmer, Milan).

\subsection{In vivo experiments}

CD1 male albino mice (20-25 g) (n=4 per group) were injected i.p. with FK866 (100 mg/kg) and sacrificed 4, 8 and $16 \mathrm{~h}$ later. Organs were rapidly collected and processed as described above for NMN content determination. Procedures involving animals and their care were conducted in compliance with the Italian guidelines for animal care (DL 116/92) in application of the European Communities Council Directive (86/609/EEC) and was formally approved by the Animal Care Committee of the Department of Pharmacology of the University of Florence.

\section{Results}

\subsection{Spectrofluorometric HPLC analysis of NMN}

Isocratic HPLC analysis of NMN with UV absorbance detection is virtually impossible because of its extremely short elution time. Indeed, under our experimental conditions (see Methods), standard NMN had a retention time of 1'54"(Fig. 2B). Addition of tetra butyl-ammonium bromide (up to $10 \mathrm{mM}$ ) to the mobile phase to increase NMN retention only minimally influenced this parameter (not shown). We were unable to identify an unequivocal peak with a retention time corresponding to NMN in a whole cellular extract from different cell lines (Fig. 2C and not shown). It is well known that $\mathrm{N}$-alkylpyridinium compounds are transformed into fluorescent compounds through reactions with ketone moieties followed by heating in acidic environment. Accordingly, methyl-nicotinamide and NAD have been quantified spectrofluorometrically for different purposes [18;20]. We therefore attempted to adapt this method to NMN measurement (see Methods). Upon derivatization, NMN became fluorescent with excitation and emission maxima at 332 and $454 \mathrm{~nm}$, 
respectively (Fig. 2D). Of note, elution time of derivatized NMN standard was increased up to 4'18'(Fig. 2E), and a single peak with the identical elution time was present in a whole cellular extract derivatized as described above (Fig. 2F). The peak area linearly increased by spiking the extract with different amounts on NMN (not shown). Optimization of the derivatization procedure showed that NMN fluorescence increased linearly by augmenting the temperature of step 2 up to $100^{\circ} \mathrm{C}$ (Fig. 2G). At this temperature, incubations longer than 5 min reduced fluorescence (Fig. $2 \mathrm{H}$ ). Maximal efficiency of step 1 was reached with derivatization times of 15 min or longer. NMN fluorescence increased linearly over the range of 8 to 2500 pmoles with a threshold sensitivity of 750 fmoles (Fig. 2l).

\subsection{Modulation of NMN content in HeLa and U937 cells}

Basal contents of NMN in U937 cells were $3,7 \pm 0.1 \mathrm{nmol} / \mathrm{mg}$ prot, and about 10-fold lower in HeLa cells $(0,48 \pm 0.02 \mathrm{nmol} / \mathrm{mg}$ prot $)$. These findings suggested low basal activity of NaPRT in HeLa cells. We therefore attempted to evaluate in intact cells the contribution of NaPRT to NMN contents by adding nicotinamide to the cell medium. As shown in Fig. 3A, nicotinamide increased NMN contents in a concentration-dependent manner in U937 but not in HeLa cells, again suggesting low expression levels/activity of NaPRT in this cell type. In contrast with this interpretation, however, addition of nicotinamide to the culture medium similarly increased NAD contents in both cell types. Taken together, these findings suggested that NaPRT is active in both U937 and HeLa cells, and that NMN does not accumulate in HeLa because of its rapid transformation into NAD by NMNAT. Reportedly, NaPRT is the rate-limiting enzyme of the mammalian NAD rescue pathway [21]. When NMN was added to the culture medium for $1 \mathrm{~h}$, its intracellular contents increased in both cells types (Fig. 1C), indicating that the nucleotide readily permeates the plasma membrane. Accordingly, NAD contents increased in both HeLa and U937 cells exposed to NMN (Fig. 3D). We also measured the subcellular distribution of NMN in these cell lines. As shown in Fig. 2E, NMN was significantly more concentrated in the mitochondrial fraction than in the cytosolic or nuclear ones. However, when subcellular NMN levels were expressed as $\%$ of total cellular content, the nucleotide amount appeared higher in the nuclear fraction (Fig. 3F). 


\subsection{Pharmacological modulation of intracellular NMN contents}

It has been repeatedly reported that, in condition of massive DNA damage, hyperactivation of the NAD-consuming enzyme poly(ADP-ribose) polymerase (PARP)-1 leads to depletion of the nucleotide pool and cell death [22]. The cell's capability to face PARP-1 dependent NAD depletion by activating the NAD rescue pathway is therefore central to cell survival. Yet, how NMN concentrations vary when PARP-1 hyperactivates is still unknown. As shown in Fig. 4A and B, exposure of U937 cells to the prototypical PARP-1 activator MNNG [23-25] only marginally increased NMN contents despite massive NAD depletion. The increase of NMN and depletion of NAD were prevented by the PARP-1 inhibitor phenanthridinone (PHE). These findings suggested that the rate of PARP-1-dependent NAD utilization exceeded that of NMNAT-mediated NAD resynthesis. However, the possibility of a compartmentalized pool of NMN not readily convertible into NAD must also be considered. Additionally, massive ATP depletion that typically follows PARP-1 activation could differently affect the activity of the ATP-dependent enzymes NaPRT and NMNAT. Gallotannin has been reported to inhibit NMNAT [26]. In keeping with this finding, we found that NMN contents increased in cells exposed to gallotannin (Fig. 4C). Evaluating the effect of the latter in cells undergoing PARP-1 hyperactivation indicated that the gallotannin- and PARP-1 activation-dependent increases of NMN were additive (Fig. 4C). FK866 is a recently identified inhibitor of NaPRT $[15 ; 16]$. It is unknown, however, whether FK866 also inhibits NMNAT. We report here that FK866 similarly reduced both NAD and NMN contents in U937 cells (Fig. 4D and E), confirming its ability to inhibit NaPRT activity. However, increases in NAD contents prompted by the addition of NMN to the culture medium were proportionally similar in the presence or absence of FK866 (Fig. 4F), indicating that the drug does not affect NMNAT activity.

\subsection{Effect of NMN or NAD on PARP-1-dependent cell death}

It has been reported that strategies aimed at increasing intracellular NAD contents provide cytoprotection under different pathological conditions [see $[2 ; 3 ; 21 ; 27]$ for reviews]. Hence, to evaluate the potential cytoprotective properties of $\mathrm{NMN}$, we analyzed various cell death 
parameters of HeLa and U937 cells undergoing NAD and ATP depletion because of PARP-1 activation. As shown in Fig. $5 A$ and $B$, both NMN and NAD were able to counteract the reduction in NAD and ATP contents in HeLa and U937 cells exposed $1 \mathrm{~h}$ to the PARP-1 activating agent MNNG. Twenty three hrs later, MNNG-challenged cells appeared shrunken and joined in clusters of dead cells. Conversely, those exposed to MNNG plus NMN or NAD in part conserved their healthy morphology (Fig. 5C). Accordingly, MTT reduction and LDH release assays showed that both NMN and NAD partially counteracted cell death $24 \mathrm{~h}$ after PARP-1-hyperactivation (Fig. 5D and E). NMN- or NAD-treated cells died $36 \mathrm{~h}$ after MNNG exposure (not shown), indicating that nucleotide cytoprotection was only transient.

\subsection{NMN content in mouse organs and effect of FK866}

To our knowledge, the impact of FK866 on NMN contents in vivo has not been reported. We therefore injected the drug in mice (100 mg/kg, i.p.) and measured NMN contents in various organs at different times after injection. Reportedly, mouse NaPRT activity is high in liver, intermediate in heart, and under detectable levels in brain [11]. Accordingly, we found that NMN contents were higher in the liver than in the heart $(6.7 \pm 0.3$ and $4.4 \pm 0.2 \mathrm{nmol} / \mathrm{mg}$ tissue, respectively). However, the brain contents of NMN $(3.86 \pm 0.1 \mathrm{nmol} / \mathrm{mg}$ tissue) were similar to those of the heart. Importantly, injection of FK866 reduced NMN contents in the three organs after 4 and 8 hrs. At 16 hrs from the injection, NMN contents in the organs were still lower than control with a tendency to return to basal values (Fig. 6).

\section{Discussion}

In the last several years we have witnessed a renewed interest in NAD biology and basic biochemistry of pyridine nucleotide metabolism [1]. Among the biochemical routes leading to NAD formation, the rescue pathway operated by NaPRT and NMNATs is of pivotal importance to NAD homeostasis in mammals. Indeed, this pathway rescues nicotinamide which is a by-product of several enzymes such as poly and mono ADP-ribose transferases, sirtuins as well as ADP-ribosyl cyclase, which are responsible for substantial consumption of NAD under constitutive and pathological conditions. However, the intracellular contents as well as subcellular 
compartmentalization of NMN, the first metabolite of the nicotinamide-dependent NAD-rescue pathway, are in large part unknown. Furthermore, whether NMN formation mediates the signalling properties of extracellular NaPRT/visfatin/PBEF waits to be clearly understood. Current lack of knowledge about the biological relevance of NMN can be ascribed, at least in part, to difficulties in nucleotide measurements in biological samples. Previous studies have quantified NMN by means of complex HPLC systems coupled to UV detection and subsequent mass spectrometry analysis $[11 ; 13 ; 28]$. Indirect methods or radioactive precursors have been also adopted to follow NMN formation and degradation [6]. In the present study, we report a new method to quantify NMN in biological samples, based on the ability of its $\mathrm{N}$-alkylpyridinium moiety to be transformed into fluorescent compounds.

By monitoring the effect of nicotinamide addition to the incubating media of HeLa or U937 cells on their NMN and NAD content, we confirm that, at least in HeLa cells, NaPRT is the rate-limiting step of the rescue pathway [29;30]. Also, evidence that intracellular NMN contents promptly increase when the nucleotide is added to the culture media indicates that plasma membrane is permeable to this nucleotide. These findings suggest that the pharmacologic effects of exogenous NMN in cultured cells and mice $[11 ; 13]$ are due to cellular uptake and changes in NAD contents. Whether NMN permeates the plasma membrane through the putative NAD uptake mechanisms [31] remains to be clarified. We also report that NMN was more concentrated in the mitochondrial fraction than in the nuclear or cytosolic ones. Although we adopted a crude cell fractionation technique with possible subcellular fraction contamination, data suggest high mitochondrial NMN contents. This finding is of particular relevance if we consider that it is still debated whether NaPRT activity is present in the mitochondria. NaPRT can be detected by Western blotting in mitochondria extracted from cultured cells or mouse liver, and the NaPRT inhibitor FK866 reduces mitochondrial NAD content when added to a pure organelle preparation [28]. Overall, these findings suggest that NMN is synthesized in mitochondria by NaPRT. Although the presence of a mitochondrial NaPRT is conceivable if we consider that mitochondria contain a specific NMNAT isoform [26], how NaPRT enters the organelles is unknown given that a mitochondrial-targeting sequence has not been reported [16]. In light of the recent identification of mitochondrial NAD carriers [28;32], the 
possibility exists that part of the mitochondrial NMN pool is uptaken from the cytoplasm. Regardless, evidence that mitochondria contain significant amounts of NMN (Fig. 3E), as well as NMNAT3 [26], clearly indicates that at least the last step of the NAD rescue pathway occurs in these organelles. This makes sense if one consider that NAD consuming enzymes such as sirtuins and mono-ADP-ribose transferases are present in mitochondria [21;33]. Conversely, the presence of a mitochondrial PARP-1 is still debated [17;34-36].

A large body of evidence identifies PARP-1 as a key player of cell death. It has been repeatedly proposed that the molecular pathway responsible for PARP-1-dependent cell death stems from an excessive consumption and ensuing depletion of NAD pools [22]. It is unknown, however, whether/how PARP-1 hyperactivation affects the kinetics of the NAD rescue pathway. We show here that the massive depletion of intracellular NAD that follows PARP-1 activation is not accompanied by a concomitant depletion of NMN. Rather, a small but significant increase in NMN content occurred upon PARP-1 activation (Fig. 4A). This finding suggests that NMNAT becomes limiting the rate of the NAD rescue pathway when the dinucleotide is massively consumed by PARP-1. Also, it indicates that strategies aimed at circumventing the "NMNAT bottleneck" could be of cytoprotective relevance in conditions of hyperactivation of PARP-1. In good agreement with this hypothesis and previous findings [37], we report that exogenous NAD reduced early PARP-1dependent bioenergetic derangement and cell death. On the one hand this result further corroborates the hypotheses that NAD depletion is causative in this type of cell demise [38], and on the other that NAD permeates through the plasma membrane [31]. Of note, NMN also reduced PARP-1-dependent energy failure and cell death, despite to a lower extent when compared to NAD. This is in keeping with the NMNAT rate-limiting activity for NAD re-synthesis during overactivation of PARP-1. We report, however, that protection afforded by NMN or NAD on cells undergoing PARP-1 hyperactivation is only transient. This indicates that the partial prevention of NAD/ATP depletion is not compatible with cell survival, and/or that delayed events in addition to nucleotide depletion [i.e. poly(ADP-ribose)-dependent mitochondrial AIF release [39]] contribute to cell demise prompted by PARP-1. Indeed, NMN can improve energy dynamics working as a 
precursor of NAD but also favour poly(ADP-ribose) formation by the detrimental NMNAT-PARP-1 complex [40].

Despite the emerging complexity and pathophysiological relevance of NAD metabolism, pharmacology of NAD re-synthesis is extremely poor, with FK866 being the most studied chemical. Evidence that gallotannin increases intracellular NMN contents (Fig. 4C) is in keeping with prior work showing that gallotannin inhibits NMNAT activity [26]. Although gallotannin is a complex mixture of tannins extracted from oak gall [41], these findings could be of relevance for the identification of the pharmacophore of more potent and specific NMNAT inhibitors. Further, the demonstration that FK866 reduced basal NMN and NAD contents in cultured cells, but did not prevent the increase of NAD in cells exposed to NMN (Fig. 4D-F), indicates for the first time that the drug selectively inhibits NaPRT, having no effects on NMNAT activity. This is of significance if one considers that the chemical is currently in clinical trial for cancer treatment [42].

In keeping with data on tissue distribution of NaPRT expression [11] and activity [43], we report that NMN is more concentrated in the mouse liver than in the heart or brain. Notably, NMN contents in the brain are comparable to those of the heart, despite evidence that NaPRT expression is almost undetectable in the brain [11]. Although we do not know the cell type(s) in which NMN is contained, data suggest active NMN uptake from neural cells. Treatment of mice with FK866 induced long-lasting but mild reduction of NAD contents in liver, heart and brain. Obviously, mild reduction can be primarily ascribed to the pharmacodynamic and pharmacokinetic features of FK866. Indeed, metabolism of FK866 is still to be clearly understood. Data, however, hint that under constitutive conditions NAD consumption and/or recycling through nicotinamide occurs at a slow rate. This hypothesis is consistent with knowledge that NAD half life in rat liver is about 10 hrs [44].

In conclusion, the development of a new method for NMM measurement allowed us to gather new information on the biochemistry and pharmacology of NAD biosynthesis. Given that the pathophysiological relevance of NaPRT and NMN is still in large part obscure, the present study helps addressing some of the numerous unanswered questions existing in the field of pyridine nucleotide metabolism and NAD signaling. 


\section{References}

1. Berger F, Ramirez-Hernandez $\mathrm{MH}$, and Ziegler $\mathrm{M}$. The new life of a centenarian: signalling functions of $\operatorname{NAD}(P)$. Trends Biochem Sci 2004;29:111-118.

2. Belenky $\mathrm{P}$, Bogan $\mathrm{KL}$, and Brenner $\mathrm{C}$. NAD+ metabolism in health and disease. Trends Biochem Sci 2007;32:12-19.

3. Magni G, Orsomando G, Raffelli N, and Ruggieri S. Enzymology of mammalian NAD metabolism in health and disease. Front Biosci 2008;13:6135-6154.

4. Magni G, Amici A, Emanuelli M, Orsomando G, Raffaelli N, and Ruggieri S. Enzymology of NAD+ homeostasis in man. Cell Mol Life Sci 2004;61:19-34.

5. Brenner C. Evolution of NAD biosynthetic enzymes. Structure 2005;13:1239-1240.

6. Bieganowski $\mathrm{P}$ and Brenner $\mathrm{C}$. Discoveries of nicotinamide riboside as a nutrient and conserved NRK genes establish a Preiss-Handler independent route to NAD+ in fungi and humans. Cell 2004;117:495-502.

7. Bogan $\mathrm{KL}$ and Brenner C. Nicotinic acid, nicotinamide, and nicotinamide riboside: a molecular evaluation of NAD+ precursor vitamins in human nutrition. Annu Rev Nutr 2008;28:115-130.

8. Yang H, Lavu S, and Sinclair DA. Nampt/PBEF/Nisfatin: a regulator of mammalian health and longevity? Exp Gerontol 2006;41:718-726.

9. Fukuhara A, Matsuda M, Nishizawa M, Segawa K, Tanaka M, Kishimoto K et al. Visfatin: a protein secreted by visceral fat that mimics the effects of insulin. Science $2005 ; 307: 426$ 430.

10. Fukuhara A, Matsuda M, Nishizawa M, Segawa K, Tanaka M, Kishimoto K et al. Retraction. Science 2007;318:565.

11. Revollo JR, Korner A, Mills KF, Satoh A, Wang T, Garten A et al. Nampt/PBEF/Visfatin regulates insulin secretion in beta cells as a systemic NAD biosynthetic enzyme. Cell Metab 2007;6:363-375 
12. Luk T, Malam Z, and Marshall JC. Pre-B cell colony-enhancing factor (PBEF)/visfatin: a novel mediator of innate immunity. J Leukoc Biol 2008;83:804-816.

13. Wang P, Xu TY, Guan YF, Su DF, Fan GR, and Miao CY. Perivascular adipose tissuederived visfatin is a vascular smooth muscle cell growth factor: role of nicotinamide mononucleotide. Cardiovasc Res 2008.

14. Rongvaux A, Shea RJ, Mulks MH, Gigot D, Urbain J, Leo O et al. Pre-B-cell colonyenhancing factor, whose expression is up-regulated in activated lymphocytes, is a nicotinamide phosphoribosyltransferase, a cytosolic enzyme involved in NAD biosynthesis. Eur J Immunol 2002;32:3225-3234.

15. Hasmann M and Schemainda I. FK866, a highly specific noncompetitive inhibitor of nicotinamide phosphoribosyltransferase, represents a novel mechanism for induction of tumor cell apoptosis. Cancer Res 2003;63:7436-7442.

16. Khan JA, Tao X, and Tong L. Molecular basis for the inhibition of human NMPRTase, a novel target for anticancer agents. Nat Struct Mol Biol 2006;13:582-588.

17. Cipriani G, Rapizzi E, Vannacci A, Rizzuto R, Moroni F, and Chiarugi A. Nuclear poly(ADPribose) polymerase-1 rapidly triggers mitochondrial dysfunction. J Biol Chem 2005;280:17227-17234.

18. Putt KS and Hergenrother PJ. An enzymatic assay for poly(ADP-ribose) polymerase-1 (PARP-1) via the chemical quantitation of $N A D(+)$ : application to the high-throughput screening of small molecules as potential inhibitors. Anal Biochem 2004;326:78-86.

19. Shah GM, Poirier D, Duchaine G, Desnoyers S, Brochu G, Lageaux J et al. Methods for biochemical study of poly(ADP-ribose) metabolism in vitro and in vivo. Anal Biochem $1995 ; 227: 1-13$

20. Musfeld C, Biollaz J, Belaz N, Kesselring UW, and Decosterd LA. Validation of an HPLC method for the determination of urinary and plasma levels of N1-methylnicotinamide, an endogenous marker of renal cationic transport and plasma flow. J Pharm Biomed Anal 2001;24:391-404. 
21. Sauve AA. NAD+ and vitamin B3: from metabolism to therapies. J Pharmacol Exp Ther 2008;324:883-893.

22. Chiarugi A. PARP-1: killer or conspirator? The suicide hypothesis revisited. Trends Pharmacol Sci 2002;23:122-129.

23. D'Amours D, Desnoyers S, and Poirier GG. Poly(ADP-ribosyl)ation reactions in the regulation of nuclear functions. Biochem J 1999;342:249-268.

24. Ha HC and Snyder SH. Poly(ADP-ribose) polymerase is a mediator of necrotic cell death by ATP depletion. Proc Natl Acad Sci 1999;69:13978-13982.

25. Yu SW, Poitras MF, Coombs C, Bowers WJ, Federoff HJ, Poirier GG et al. Mediation of poly(ADP-ribose) polymerase-1-dependent cell death by apoptosis-inducing factor. Science 2002;297:259-263.

26. Berger F, Lau C, Dahlmann M, and Ziegler M. Subcellular compartmentation and differential catalytic properties of the three human nicotinamide mononucleotide adenylyltransferase isoforms. J Biol Chem 2005;280:36334-36341.

27. Porcu $M$ and Chiarugi $A$. The emerging therapeutic potential of sirtuin-interacting drugs: from cell death to lifespan extension. Trends Pharmacol Sci 2005;26:94-103.

28. Yang H, Yang T, Baur JA, Perez E, Matsui T, Carmona JJ et al. Nutrient-sensitive mitochondrial NAD+ levels dictate cell survival. Cell 2007;130:1095-1107.

29. Revollo JR, Grimm AA, and Imai SI. The NAD biosynthesis pathway mediated by nicotinamide phosphoribosyltransferase regulates Sir2 activity in mammalian cells. J Biol Chem 2004.

30. Pillai JB, Isbatan A, Imai S, and Gupta MP. Poly(ADP-ribose) polymerase-1-dependent cardiac myocyte cell death during heart failure is mediated by NAD+ depletion and reduced Sir2alpha deacetylase activity. J Biol Chem 2005;280:43121-43130.

31. Billington RA, Travelli C, Ercolano E, Galli U, Roman CB, Grolla AA et al. Characterization of NAD uptake in mammalian cells. J Biol Chem 2008;283:6367-6374.

32. Todisco S, Agrimi G, Castegna A, and Palmieri F. Identification of the mitochondrial NAD+ transporter in Saccharomyces cerevisiae. J Biol Chem 2006;281:1524-1531. 
33. Richter C, Winterhalter $\mathrm{KH}$, Baumhuter S, Lotscher HR, and Moser B. ADP-ribosylation in inner membrane of rat liver mitochondria. Proc Natl Acad Sci U S A 1983;80:3188-3192.

34. Du L, Zhang X, Han YY, Burke NA, Kochanek PM, Watkins SC et al. Intra-mitochondrial poly-ADP-ribosylation contributes to NAD+ depletion and cell death induced by oxidative stress. J Biol Chem 2003;278:18426-18433.

35. Scovassi Al. Mitochondrial poly(ADP-ribosylation): from old data to new perspectives. FASEB J 2004;18:1487-1488.

36. Niere M, Kernstock S, Koch-Nolte F, and Ziegler M. Functional localization of two poly(ADP-ribose)-degrading enzymes to the mitochondrial matrix. Mol Cell Biol 2008;28:814-824.

37. Ying W, Garnier P, and Swanson RA. NAD+ repletion prevents PARP-1-induced glycolytic blockade and cell death in cultured mouse astrocytes. Biochem Biophys Res Commun 2003;308:809-813.

38. Berger NA. Poly (ADP-ribose) in the cellular response to DNA damage. Radiat Res $1985 ; 101: 4-15$

39. Yu SW, Andrabi SA, Wang H, Kim NS, Poirier GG, Dawson TM et al. Apoptosis-inducing factor mediates poly(ADP-ribose) (PAR) polymer-induced cell death. Proc Natl Acad Sci U S A 2006;103:18314-18319.

40. Berger F, Lau C, and Ziegler M. Regulation of poly(ADP-ribose) polymerase 1 activity by the phosphorylation state of the nuclear NAD biosynthetic enzyme NMN adenylyl transferase 1. Proc Natl Acad Sci 2007;104:3765-3760.

41. Formentini L, Arapistas P, Pittelli M, Jacomelli M, Pitozzi V, Menichetti S et al. Mono-galloyl glucose derivatives are potent poly(ADP-ribose) glycohydrolase (PARG) inhibitors and partially reduce PARP-1-dependent cell death. Br J Pharmacol 2008.

42. Holen K, Saltz LB, Hollywood E, Burk K, and Hanauske AR. The pharmacokinetics, toxicities, and biologic effects of FK866, a nicotinamide adenine dinucleotide biosynthesis inhibitor. Invest New Drugs 2008;26:45-51. 
43. Dietrich LS, Fuller L, Yero IL, and Martinez L. Nicotinamide mononucleotide pyrophosphorylase activity in animal tissues. J Biol Chem 1966;241:188-191.

44. Ijichi $\mathrm{H}$, Ichiyama $\mathrm{A}$, and Hayaishi $\mathrm{O}$. Studies on the biosynthesis of nicotinamide adenine dinucleotide. 3. Comparative in vivo studies on nicotinic acid, nicotinamide, and quinolinic acid as precursors of nicotinamide adenine dinucleotide. J Biol Chem 1966;241:3701-3707.

\section{Acknowledgments}

This study was supported by grants from the University of Florence, the Italian Ministry of University and Scientific and Technological Research, Associazione Italiana Sclerosi Multipla and Ente Cassa di Risparmio di Firenze.

\section{Figure legends}

Figure 1. Derivatization of NMN. NMN is converted into a fluorescent compound upon reaction with acetophenone and formic acid.

Figure 2. Optimization on HPLC analysis of NMN. (A) NAD biosynthetic pathways in mammals. NAD is synthesized de novo through the kynurenine pathway originating from tryptophan. Intracellular NAD degrading enzymes such as PARPs, mono(ADP-ribosyl)transferases (MARTs) and Sirtuins hydrolyze NAD forming different products and nicotinamide (NAM). The later is utilized to re-synthesize NAD through the NAD rescue pathway including NaPRT and NMNAT1-3. Nicotinic acid (NA) originating from food is transformed into NAD through the Preiss-Handler pathway composed by NA phosphoribosyl transferase (NAPRT), NMNAT1-3 and NAD deamidase (NADASE). Nicotinamide riboside kinase (NRK) converts nicotinamide riboside (NR) into NMN. The site of action of the NaPRT inhibitor FK866 is shown. (B), Chromatogram of NMN (250 pmol) obtained with an HPLC apparatus coupled to an UV detector (see Methods). (C), Chromatogram of a whole cell extract (U937 cells) injected into the same apparatus described in (B). (D), Absorption and emission spectra of NMN derivatized as described in Methods. (E), Chromatogram of 
derivatized NMN (250 pmol) obtained with an HPLC apparatus coupled to a fluorimetric detector (see Methods). (F) Chromatogram of a whole cell extract (U937 cells) derivatized as described in Methods and injected into the same apparatus described in (E). (G) Effect of the temperature of the step 2 of the derivatization procedure on efficiency of NMN derivatization. $(\mathrm{H})$ Effect of duration of step 1 or 2 of the derivatization procedure on efficiency of NMN derivatization. (I) NMN calibration curve. Fluorescence of NMN is linear up to 2500 pmol injected. In G-I, bars/points represent the mean \pm SEM of three experiments conducted in duplicate.

Figure 3. NMN and NAD contents in HeLa and U937 cells. NMN and NAD contents were measured in HeLa and U937 cells under control conditions or after exposure for $1 \mathrm{~h}$ to different concentrations of nicotinamide (Nam) (A and B) or NMN (C and D). (E, F) Contents of NMN in cytosol, nuclei and mitochondria of HeLa or U937 cells. ${ }^{*} p<0.05,{ }^{* *} p<0.01$ vs Cytosol (ANOVA + Tukey's post hoc test). In A-E, each point/bar represents the mean \pm SEM of three experiments conducted in duplicate.

Figure 4. Effect of PARP-1 activation, gallotannin or FK866 on NMN or NAD contents in U937 cells. The NMN (A) or NAD (B) contents were measured in cells under control conditions and at different times after exposure to the PARP-1-activating agent MNNG $(100 \mu \mathrm{M})$ in the presence or absence of the PARP-1 inhibitor phenanthridinone (PHE, $30 \mu \mathrm{M})$. (C) The contents of NMN were measured in cells exposed for $1 \mathrm{~h}$ to different concentrations of gallotannin (GLT) in the presence or absence of MNNG $100 \mu \mathrm{M} / 1 \mathrm{~h}$. Effect of a $4 \mathrm{hrs}$ exposure to FK866 on intracellular NMN (D) or NAD (E) contents. (F) NAD contents in cells exposed $1 \mathrm{~h}$ to different concentrations of NMN and preincubated $4 \mathrm{hrs}$ with FK866 $(10 \mu \mathrm{M})$. Each bar represents the mean \pm SEM of at least three experiments conducted in duplicate. ${ }^{*} p<0.05,{ }^{* *} p<0.01$ vs Crl (ANOVA + Tukey's post hoc test). In (F) §p<0.05 vs Crl in the presence of FK866 (ANOVA + Tukey’s post hoc test).

Figure 5. Cytoprotection form PARP-1-dependent cell death by NMN or NAD. Effect of NMN or NAD added to the incubating media of HeLa and U937 cells (1 h preincubation) on reduction of 
NAD (A) or ATP (B) contents prompted by $1 \mathrm{~h}$ exposure to $100 \mu \mathrm{M}$ MNNG. (C) Phase contrast visualization of the two cell types under control conditions or $11 \mathrm{hrs}$ after $1 \mathrm{~h}$ exposure to MNNG in the presence or absence of NMN or NAD, both at $1 \mathrm{mM}$. The two nucleotides were present during and after MNNG exposure. Effect of NMN or NAD added to the incubating media of HeLa and U937 cells on MTT reduction (D) or LDH release (E) evaluated $11 \mathrm{hrs}$ after $1 \mathrm{~h}$ exposure to 100 $\mu M$ MNNG. The two nucleotides were present during and after MNNG exposure. Each bar represents the mean \pm SEM of at least three experiments conducted in duplicate. In (C) representative images of three experiments are shown. ${ }^{*} p<0.05$, ${ }^{* *} p<0.01$ vs MNNG (ANOVA + Tukey's post hoc test). In (C), bar $=40$ or $20 \mathrm{~nm}$ for HeLa and U937, respectively.

Figure 6. Effect of FK866 on NMN contents in different mouse organs. NMN was measured in different mouse organs under control conditions (C) and at different times after i.p. injection of FK866 (100 mg/kg). Each bar represents the mean of 2 experiments ( $n=4$ per group). ${ }^{*} p<0.05$ vs C (ANOVA + Tukey's post hoc test). 


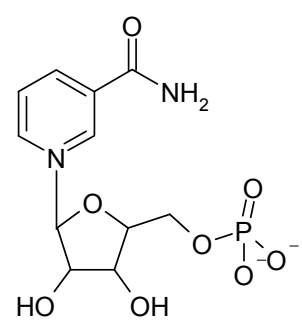

NMN

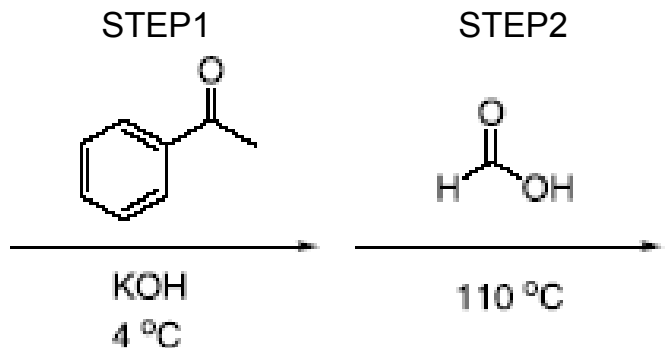

NMN derivatized

Figure 1 


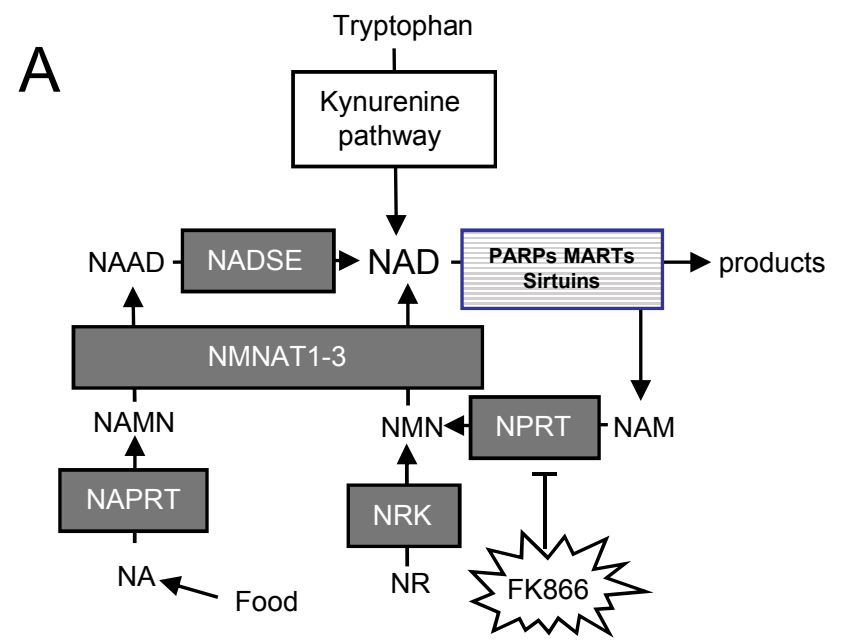

B

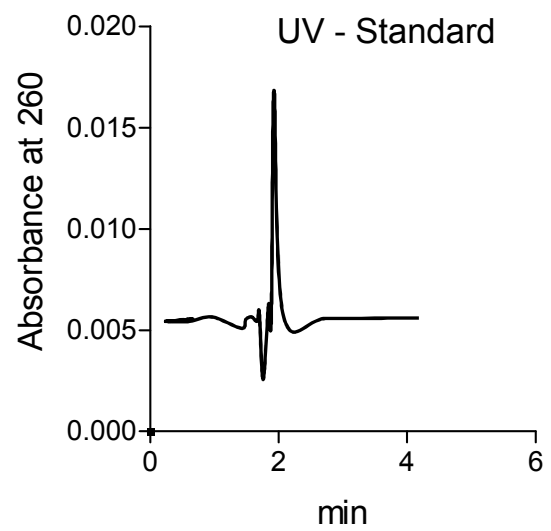

C

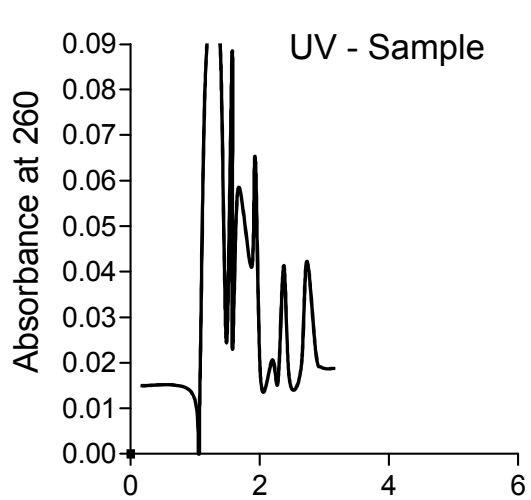

E

$\min$

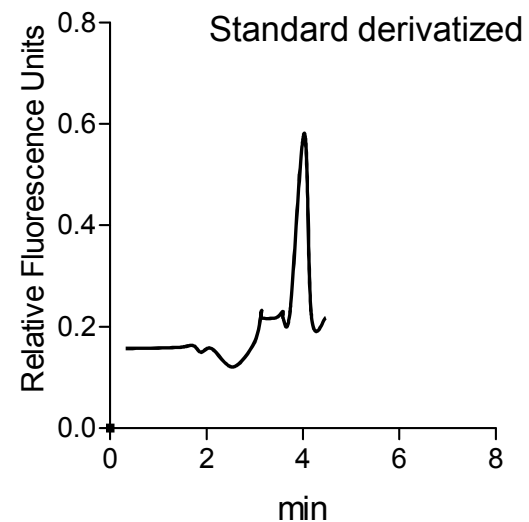

F
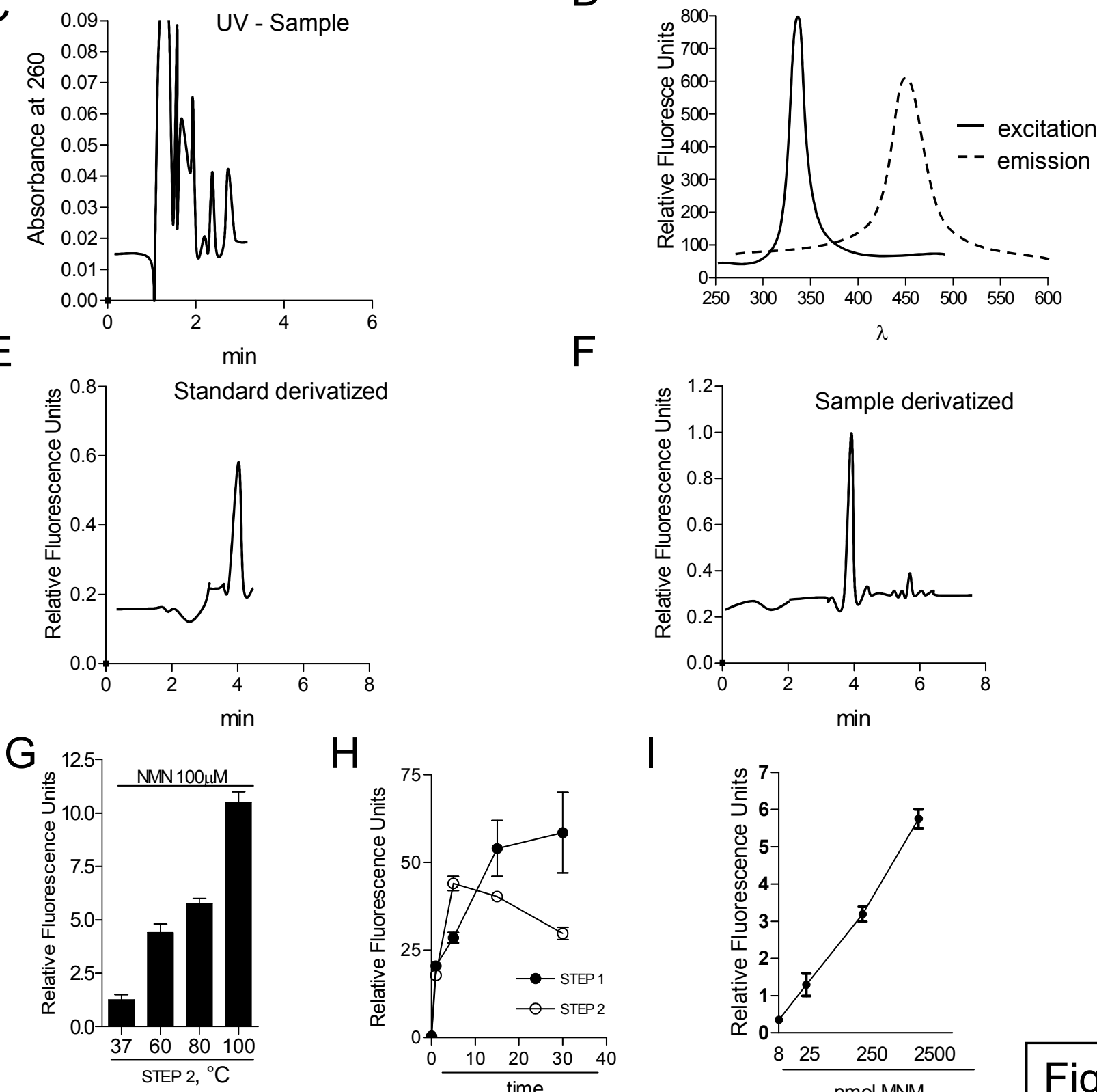

$\mathrm{H}$
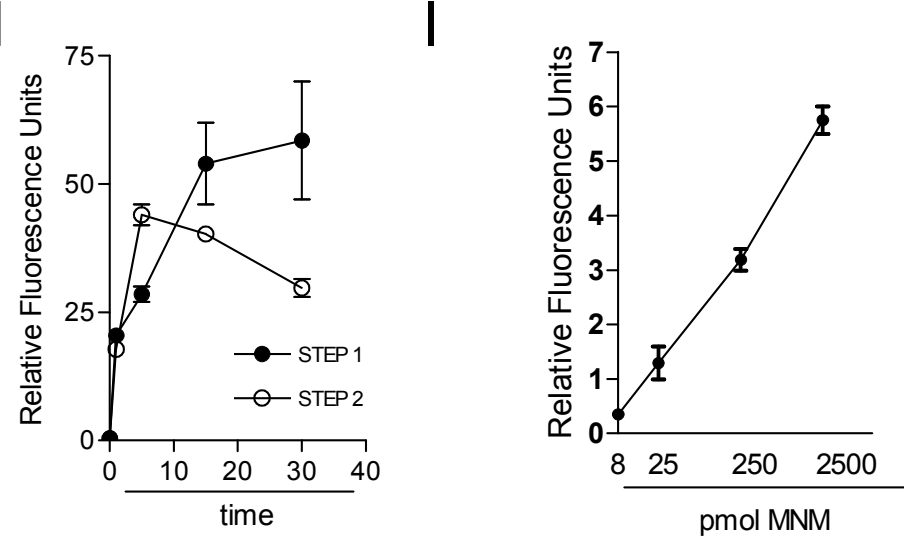

Figure 2 
A

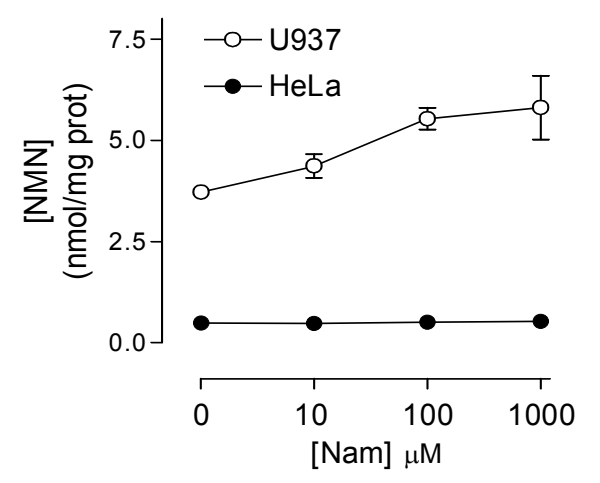

C

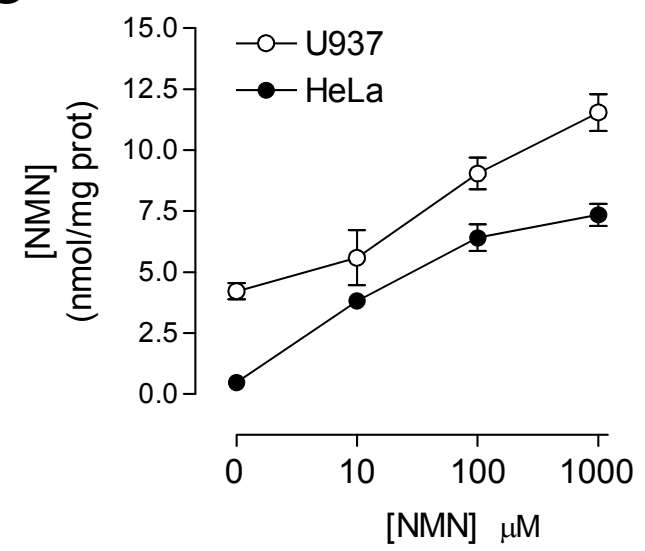

E

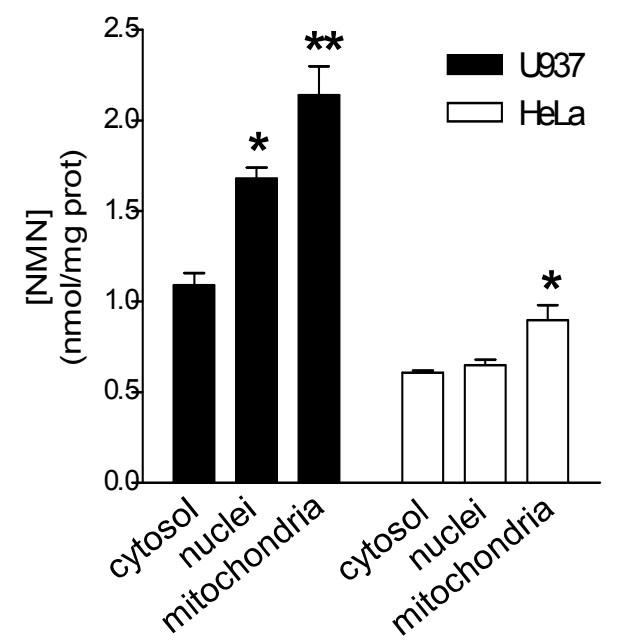

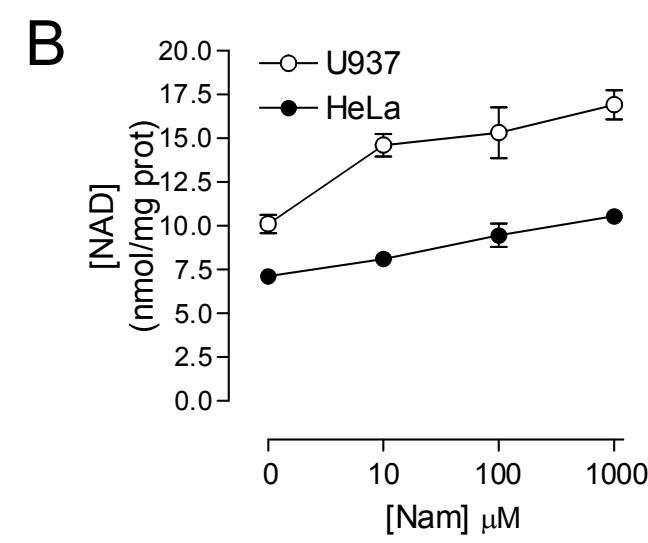

D

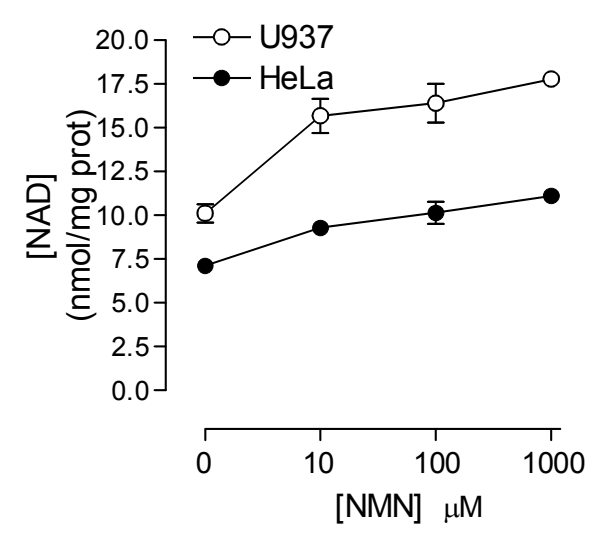

F

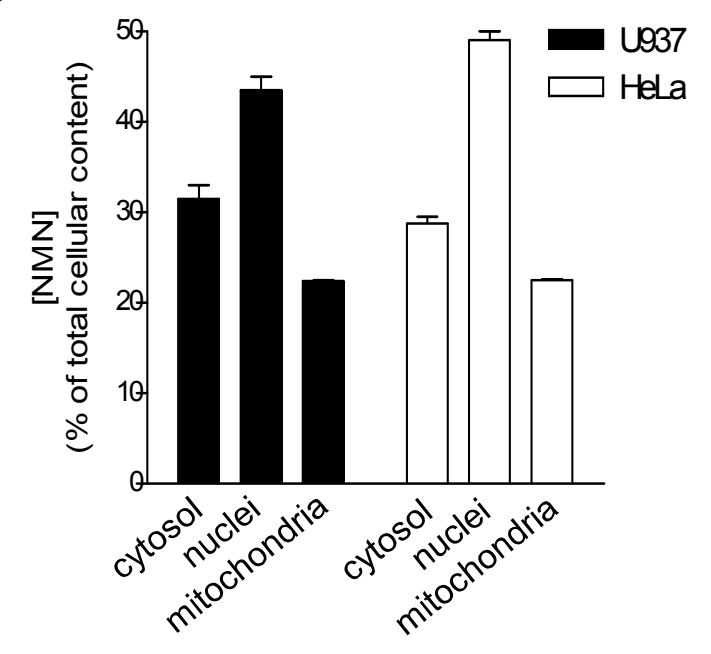

Figure 3 
A
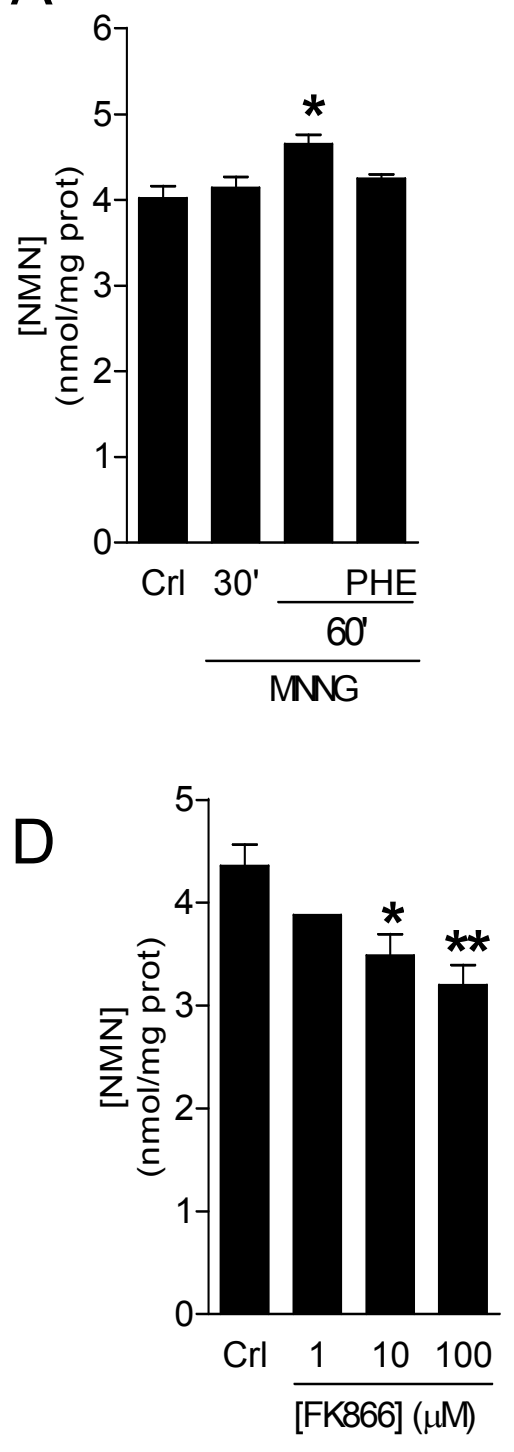

B
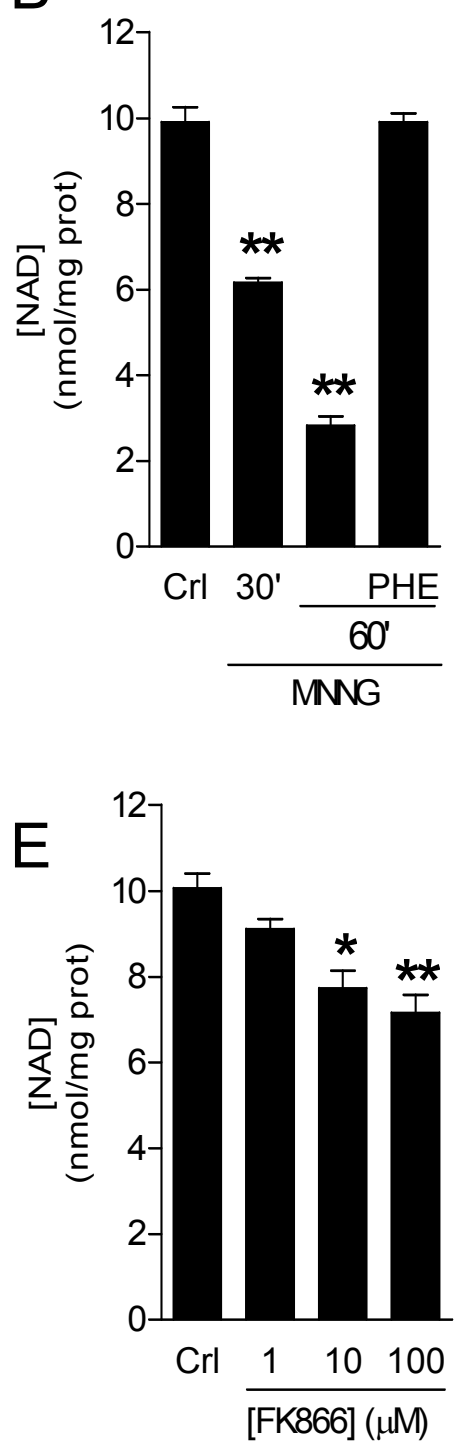

C
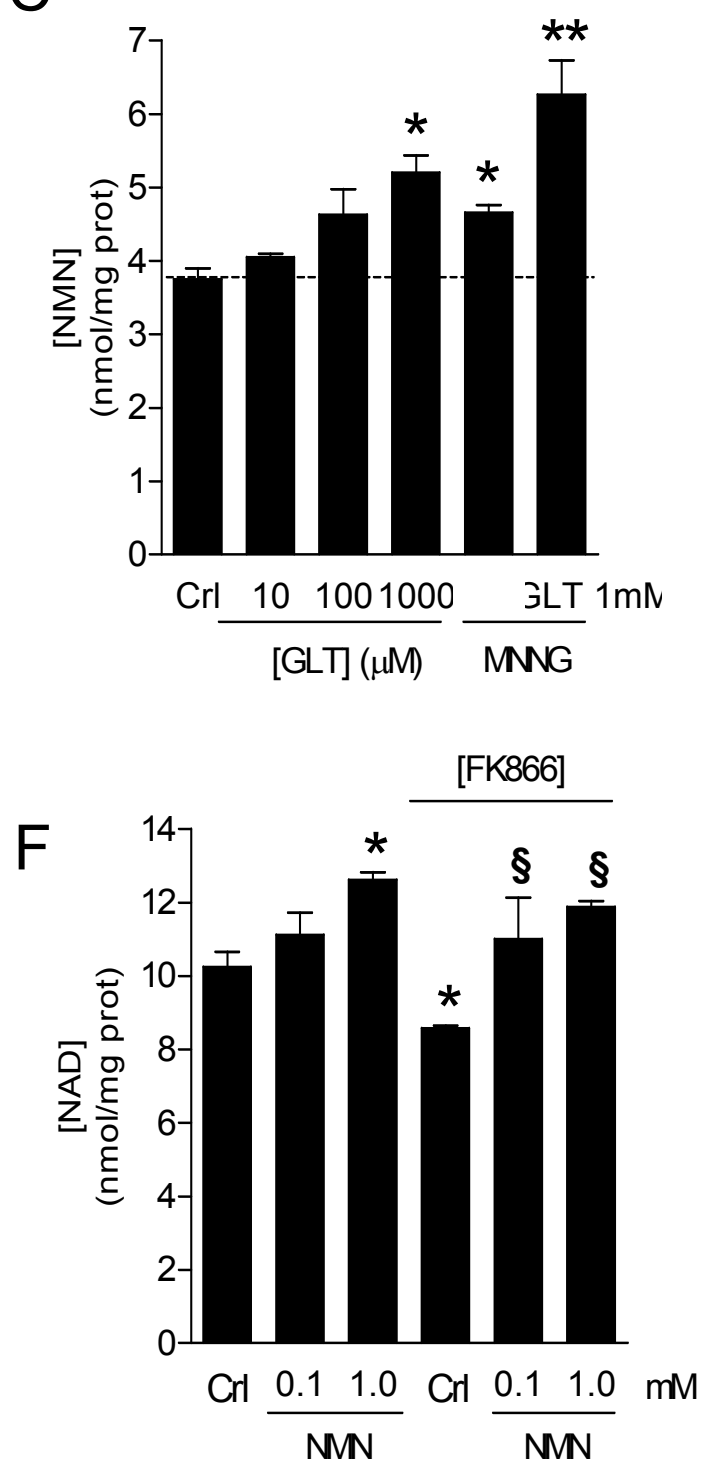

Figure 4 
A

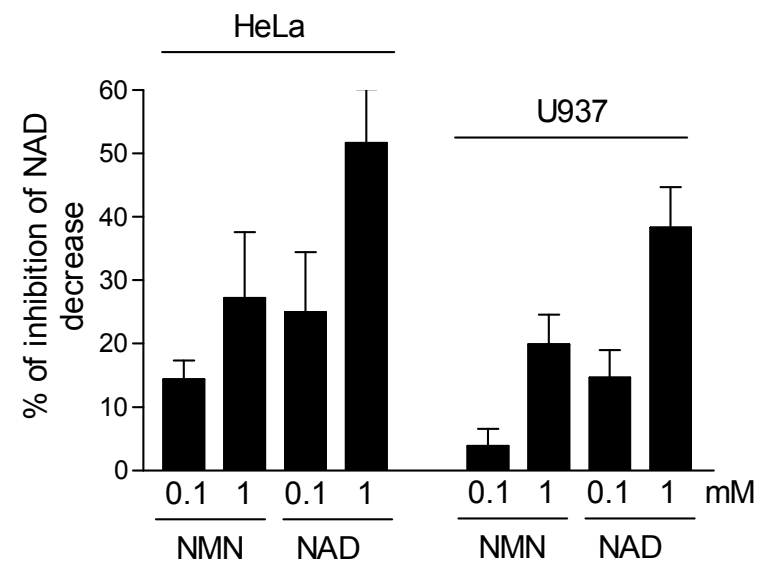

B

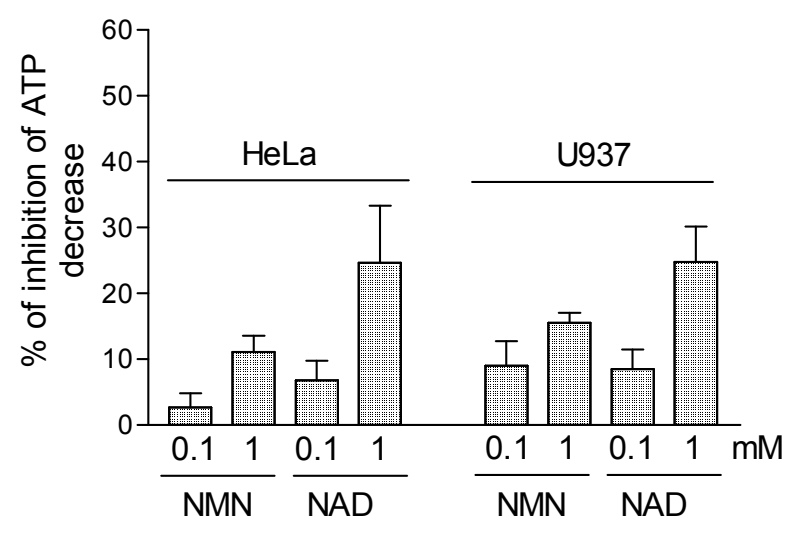

C
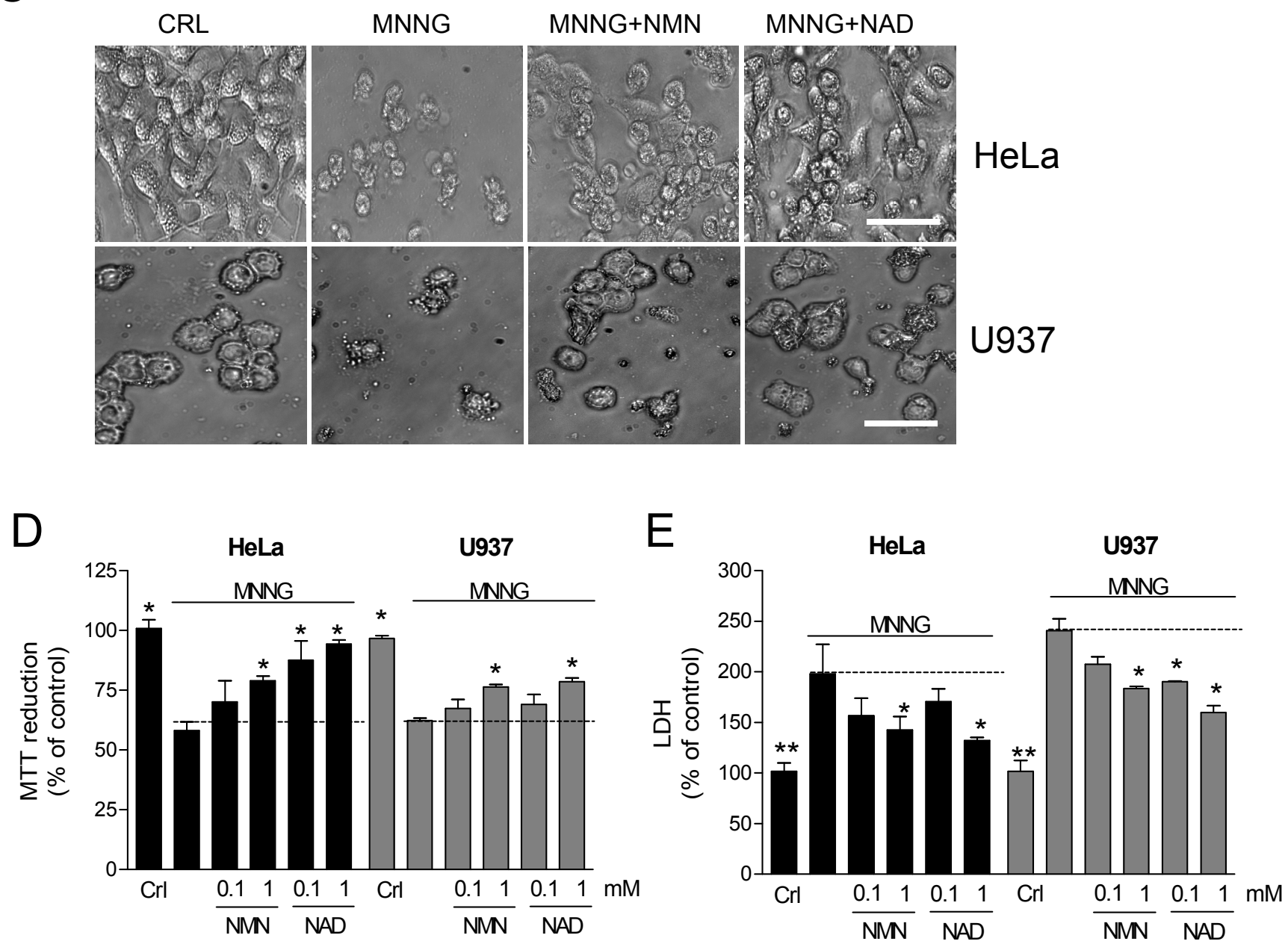

Figure 5 


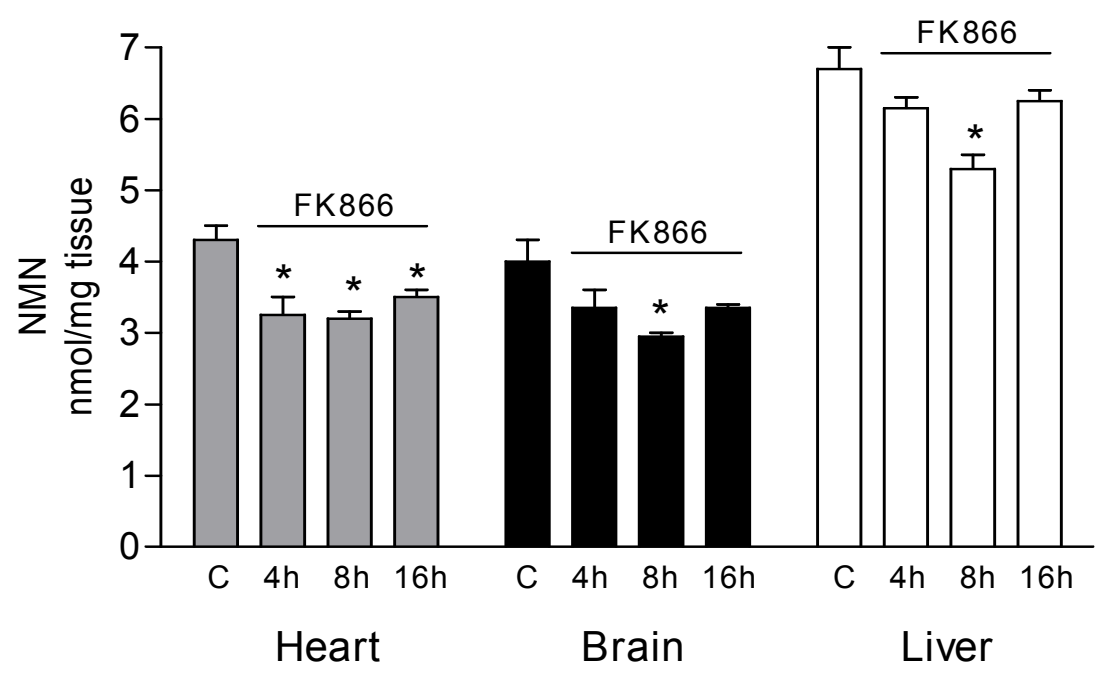

Figure 6 